ISSN 1112-9867

http://www.jfas.info

\title{
COMBATING SUBSTANCE ABUSE WITH THE POTENTIAL OF GEOGRAPHIC INFORMATION SYSTEM COMBINING MULTIVARIATE ANALYSIS
}

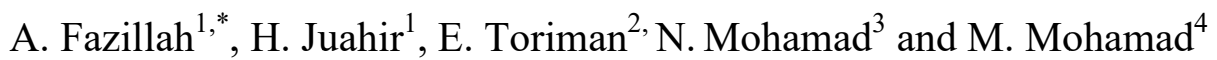 \\ ${ }^{1}$ East Coast Environmental Research Institute, Universiti Sultan Zainal Abidin, Gong Badak \\ Campus, 21300 Terengganu, Malaysia \\ ${ }^{2}$ School of Social Development and Environmental Studies, Faculty of Social Science and \\ Humanities, National University of Malaysia, 43600 Bangi, Selangor, Malaysia \\ ${ }^{3}$ Faculty of Medicine, Universiti Sultan Zainal Abidin, 20400 Terengganu Malaysia \\ ${ }^{4}$ Faculty of Economics and Management Sciences, Universiti Sultan Zainal Abidin, Gong \\ Badak Campus, 21300 Terengganu, Malaysia
}

Published online: 08 August 2017

\begin{abstract}
Substance abuse problems have been a growing concern for people from all over the world. The objective of this study is to demonstrate the usefulness of a combination between a geographic information system and a multivariate analysis in substance abuse research. However, due to the limited studies on a combination of both these methods in the substance abuse field, we review some other studies in various fields indicating the potential of this method in future substance abuse studies. As the expertise of GIS lies in spatial analysis and the multivariate analysis lies in analyzing huge data thus being capable of interpreting the results very well, we hope this method will attract researchers to applying it in their studies and can consequently and indirectly help in combating substance abuse problems.
\end{abstract}

Keywords: substance abuse; geographic information system; multivariate analysis; spatial analysis; combat.

Author Correspondence, e-mail: fazillah1988@gmail.com

doi: http://dx.doi.org/10.4314/jfas.v9i2s.32 


\section{INTRODUCTION}

A drug is a substance widely used in medicine, particularly in obtaining relief from pain and stress [1]. On the other hand, drugs are also used in various cultures for a variety of reasons, including religious purposes and for recreation to alter consciousness. Although originally drugs were beneficial for many purposes, the abuse of this substance has caused an adverse effect not only to the abuser itself but also to the society and the state as a whole. Substance abuse related to undesirable health effects and other social problems is seen to be a major issue worldwide, since there are an increasing number of substance abusers and there is the emergence of new psychoactive substances [2]. According to [3], the World Health Report 2002 has expressed that the total burden of disease worldwide due to psychoactive substance abuse was at $8.9 \%$, and this included tobacco, alcohol and illicit drugs.

This problem does not discriminate between gender, age and socioeconomic status, despite many researches relating substance abuse with males [4-6], low education [7-9] and low socio economic class [10-11] because some studies had proven otherwise [12-13]. Other than that, there were many studies on substance abuse among adolescents [14-15] in which the highest substance abusers were among them. The most common substances that are abused worldwide are opiate, cocaine, amphetamine and cannabis, but the consumption patterns always change [16]. These substances giving different impacts to the substance abuser according to the type of substance. However, the general impact of causing violence is very worrying to the government because substance abuse is synonymous with crime [17].

Various attempts have been made by governments worldwide to solve this problem by spending highly on research, rehabilitation programs and treatment centers. However, until today, this issue remains a threat to the entire world because the effect arising from the abuse of substances has an impact on health, economy and society. However, a majority of substance abusers do not seek or use the treatments provided. Releasing one of the barriers to the rehabilitation process among substance abusers is closely related to geographical conditions, and GIS was seen to visualise a clear picture of these issues through a map generated.

The idea of using GIS for substance abuse research was made aware to the researchers when 
they found out that there was a strong association between diseases and environmental surroundings [18]. Through spatial analysis in GIS, this system was believed to be able to bring a future hope for the researcher to overcome this issue. This is the same for substance abuse cases which are considered a type of disease. Researchers in this field have forwarded this method with the hope of helping relevant stakeholders to plan the best solution to eradicate these problems. GIS was known as a powerful tool in spatial analysis through the ArcGIS software. The concept of spatial analysis is broad, covering an analysis on the data which is linked to the coordinates on the map. The spatial data such as coordinate (latitude, longitude) then will be merged with the other data [19]. The data can be integrated using the ArcGIS software using geographical and non-geographical data, which is then linked together to generate the needed information [20]. Among the popular spatial analysis in epidemiology research is spatial clustering and spatial detection [21-22].

On the other hand, the statistical analysis will explore the data set and interpret the data which is difficult to understand at a glance. One of the most popular statistical analysis tools used to explore the complexity of the data is the multivariate analysis. The multivariate analysis is widely used in environmental research [23] and it is deemed to be the best method for preventing a misinterpretation of a vast amount of data and drawing meaningful information [24]. The most common multivariate analysis used is factor analysis, principle component analysis, hierarchical algorithm cluster analysis and discriminant analysis which can isolate the data into specific clusters [25].

Monitoring the trend of substance abuse cases is an important aspect in preventing more serious problems from occurring. These trends could serve as an aspect for the stakeholders involved to enhance the prevention and awareness programs. Multivariate coupling with geographic information system mapping tools for many research areas have proven beneficial for understanding the situation of the problem and proper planning could be suggested to overcome the problem. Therefore, this study investigates the innovative technique of the application of the Geographic Information System (GIS) combining statistical analysis in understanding the substance abuse problem and thus planning a better solution. 


\section{GIS CONCEPT}

Various definitions have been given to GIS. However we conceptualized GIS as a computer based system to integrate, analyze and visualize the information using a map [26]. GIS supports the analysis of huge data and a large quantity of information coming from a variety of sources [27]. The data in GIS is divided into attribute and spatial data which is regarded as the main function of GIS [28]. GIS provides a convenient way for data analysis to integrate large, spatially referenced data concerning various geographical aspects in the spatial database [29]. The capability of GIS lies in the ability to analyze and manipulate data based on its spatial location [30]. A complete set data from a variety sources that will undergo the georeferencing process can be quickly assembled for the particular map and expedite the management process [31]. GIS is universally beneficial for data preparation and visualization [32].

The potential of GIS in the health care industry has gradually been recognized by researchers. It is continuously used to communicate health problems and find solutions. The capability of GIS is to superimpose each layer containing available information in the specific location and try to discover a meaningful analysis, thus providing a better understanding and giving new insights into the relationship between geographical location given by information in each layer such as causal factors and potential area of diseases [33].

The end product of GIS in producing a disease map contains a lot of information. GIS mapping techniques are a helpful tool for any researcher to visualize and analyze the collected data immediately [34]. By the visual presentation of map, the distribution of particular diseases related to other factors may be analyzed and better understood, and amazingly this sophisticated GIS may be even used for disease prediction [29].

\section{MULTIVARIATE ANALYSIS CONCEPT}

In order to avoid misunderstanding and losing data, a multivariate analysis can serve as an unbiased technique which is really helpful to analyze data and indicate variable association among samples [35]. Multivariate techniques encompass a variety of methods that has proven to be able to easily analyze and handle a lot of data accurately [36]. In the present paper, we discuss only some multivariate analysis techniques which were found to be used for some 
kind of research. These are the principle component analysis (PCA)/factor analysis (FA), hierarchical algorithm cluster analysis (HCA) and discriminant analysis (DA).

PCA/FA is acknowledged as a pattern recognition technique that tries to reduce the dimensionality of data and converts them into smaller sets of independent variables [37-38]. This method describes the whole data with a minimum loss of information [39] and explains the variance of a large dataset of inter-correlated variables with a smaller set of independent variables [38].

A cluster analysis is an unsupervised pattern recognition technique that uncovers the intrinsic structure or underlying behaviour of a dataset without making a priori assumptions about the data in order to classify the data into the same clusters based on their nearest similarities [40]. The result will group the cluster by their unique characteristics, grouping the similarities of data within a group (showing strong homogeneity within group) and dissimilarities of data among different groups (showing strong heterogeneity among groups) [41].

Eventually, the end result of the cluster analysis will be visualized through a dendogram [42]. Opposite to the cluster analysis, a discriminant analysis will be performed with priori assumptions of the membership of objects to particular groups [36]. A discriminant analysis aims to discriminate the variable between groups based on certain predictor variables [43]. The variance covariance between the groups were maximized and the variance covariance within the classes were minimized under a simultaneous concentration of all analyzed features [44]. It constructed a discriminant function for each group which combines information from predictor variables to maximize the discrimination among the groups [45].

\section{GENERAL REVIEW ON THE COMBINATION OF GIS AND MULTIVARIATE} ANALYSIS

The combination of a multivariate analysis and the GIS may be intertwisted by either doing a multivariate analysis after the GIS processes or otherwise. Some studies analyse the data and export the results into the GIS tool and some others use a multivariate analysis after the GIS processes to confirm the result. Both methods can be used depending on the study goals. Due to a lack of spatial statistical tools in GIS, other statistical analysis techniques such as a 
multivariate analysis may help to enhance the study [46]. The multivariate analyses that will be focused on here include the PCA/FA, CA and DA which are used widely in water quality assessment [47]. Using this powerful analysis, we are trying to highlight the capability of these techniques in analyzing and thus interpreting data. Therefore, we examine the application of these methods in other fields according to the advantages of combining these methods and this is expected to give a view on the ability of these methods to be applied in the substance abuse field. Generally, a factor analysis or principle component analysis is one of the most powerful methods for reducing the dimensionality of a huge data set without losing any information [39]. Numerous studies have used PCA as a pre-processing method [48] to determine variation patterns of geochemical variables [49-50] and reducing the dimensionality of highly dimensional data [35, 51-52]. Subsequently, through the adding of GIS through data exporting as well as a result of analysis into the GIS tool for further analysis, better visualization can be enhanced.

There has been a lot of research using a combination of GIS and PCA in other studies. In [53] has proposed a combination of PCA and GIS in a study where PCA will determine the most influential variables and the weights based on the percentage of variability explained, thus embedding the result into GIS to produce a map. A variety studies in the groundwater field have applied this combination method. As studied by [54] using multivariate analysis such as PCA and CA in their study for the studying of hydro chemical patterns of watersheds significantly helped to discover groundwater classifications and discover major factors influencing groundwater quality chemistry. Hence, creating a surface map using GIS to visualize the spatial distribution of TDS and the relationship with hydro chemical water types and sample cluster and a surface a map visualizing spatial distribution of contribution of individuals are the three principal components generated by PCA. Another study by [55] has tried to propose the innovation of joining multivariate analysis (HCA and FA) with GIS and other conventional graphical methods to determine spatial groundwater types and the spatial variation of the major sources of hydro chemical changes in Ghana after some literature successfully revealed the popularity of multivariate analysis in geo environmental studies [50, 56]. 
Another study on agricultural soils by [57] also applied a combination of multivariate analysis and the GIS method. In their study, FA coupled with HACA was used to identify the spatial factors associated with the pollution of heavy metals in the study area. Hence, the result was imported into the ArGIS software to produce a spatial pattern of the heavy metals. A previous study on mapping regional groundwater chemistry zones in the Fitzroy basin using statistical and conceptual methods by [58] used a multivariate analysis (CA) to sort the water types then visualized them via GIS. Then, spatial zones had to be managed. Another study by [59] used PCA and CA to identify the variation of water quality and identify the pollution sources in Muttukadu Backwater and further analyze water quality using the interpolation method in ArcGIS software. In a study by [60], the PCA was used to find the structure in the relationships between variables which were then entered into the logistic model for predictive model fitting. Subsequently, the outcome of model was introduced into the GIS to let the model run. In the end, a map of the predictive land cover distribution was produced.

Mostly, our review found out that many studies used GIS after the multivariate analysis part was done for data visualization through a map. However, the capability of GIS on analyzing data was not limited to that, though it could be enhanced through a spatial analysis in the ArcGIS tool to analyze the data which was linked to the specific coordinate. For example, in a study by [61] using the GIS spatial analysis tool, the land use, slope, DEM and administrative map was used to calculate the watershed characteristics for each sampling site and the PCA was used to find the major gradients and principal patterns in the water quality data between wet and dry seasons, thus exploring the spatial and temporal variation in river water quality in the study area. Besides that, GIS can also make a spatial analysis for the identification of hot spot areas [62]. In [63] performed a spatial autocorrelation analysis to measure geographic patterns and cluster analysis for cases of cancer incidents in their study. This method was also applied by [64]. A map of cancer produced by [65] was improved by an augmentation of the map through overlaying the reliable information and spatial autocorrelation. A spatial arrangement of data in a study by [66] was investigated through an ordinary kriging in GIS. Thus, the Krigs map generated presented a distribution of groundwater quality parameters. Other than that, the multivariate analysis and GIS share the same aptitude in analyzing data 
such as in constructing an index and the clustering analysis. Heretofore, FA and PCA were a primary method for index construction in several studies [67-68]. Previous studies has proven that the indices could also be constructed using GIS. For example, a study by [69] has proposed the use of GIS for index construction. In that paper, multicriteria analysis (MCA) techniques were used to strengthen the value of deprivation indices constructed from qualitative data sources.

\section{INTEGRATION OF GIS AND MULTIVARIATE ANALYSIS IN SUBSTANCE} ABUSE STUDY

From the community health overview, GIS was seen as powerful evidence-based practice tool for early problem detection and solving [70]. The visual presentation and distribution of any particular disease and association to any factor may be presented using a map will lead to identifying the impact of those diseases to the population, and hence it may help in identifying risk areas for further action. The capability of GIS in managing both spatial and non-spatial information provides an excellent framework for disease management [71]. In [70] considered that GIS could act as more powerful methods when coupled with statistical methods for enhancing the validity and make robust conclusions. The combination of GIS and other spatial statistical methods provide a fuller exploration on the way diseases are distributed and affect the surrounding people [72]. To that, even more studies applied the GIS and multivariate analysis. Nevertheless, there has been limited research in the public health field particularly in substance abuse, using a combination of these two methods.

GIS may be one of the most important tools for the advancement in the public health sector [73]. Several researchers have demonstrated the usefulness of GIS within public health studies. There are a few studies with the application of GIS in public health. For example, studies on the analysis of access to treatment centers [74-76]. There are also studies examining the impact of distance [77], developing a map for planning prevention of the diseases [27, 34], identifying the spatial distribution of the diseases [78-79, 62] and identifying hot spot areas to determine the potential risk areas of the disease [80-81, 71]. All studies above used spatial analysis in the ArcGIS software. 
There is no doubt some studies using GIS can be applied in substance abuse research as shown by studies by [82-83] in which applying GIS in their studies towards drug users to inform of the formation and optimization of public health intervention, hence providing a greater understanding of at risk drug user populations. Besides that, there is also a variety of research in substance abuse studies applying GIS to determine the spatial distribution of drug users [84-85], evaluating travel distance and the availability of substance abusers to treatment centers [86-88], identifying environmental factors associated with substance abuse [15, 89-90] and assessing neighbourhood factors to effective outcome treatment to substance abuser [91-93]. However, improving computer technology such as GIS may enhance substance abuse research as a previous study by [79] had used a combination of GIS and multivariate analysis to analyze the spatial and temporal distribution of drug addicts to understand the geographical distribution of drug addicts which fall into the same cluster. In this study, they analyze data using the CA then transfer the result to GIS for visualization purposes.

To date, there has been limited research on using multivariate analysis for substance abuse studies. Most of them use FA/PCA geared towards determining a factor structure in their constructed questionnaires for substance abuse [94-95]. Earlier studies by [96] stated that substance abuse research like prevention purposes lack statistical analysis to analyze data, causing the power of analysis miss to detect prevention approaches. Because of that, the sophistication of statistical analysis such as multivariate analysis becomes necessary in substance abuse study due to the complex set of data. The advances in extracting information and the appropriate adjusting of a unique value of substance abuse data may lead to an accurate interpreting and concluding of research studies [97]. This makes a combination of GIS and multivariate analysis a potentially powerful tool for substance abuse studies. Hence, we propose the combination of methods may be used as an integrational tool to link substance abuse data together through a geographical reference system of substance abuse. This may be helpful to enhance the power of analysis and the interpretation of results in a convincing way.

\section{CONCLUSION}

This paper attempted to introduce a methodology of combining multivariate analysis and GIS 
for substance abuse research in identifying the risk factors, assessing distribution areas and identifying hot spot areas and cold spot areas and thus planning for the best solution with other stakeholders on eradicating substance abuse problems in this country. Most studies on this combining method are gotten through revising other studies from various fields. Based on our view, this method is very exciting to be applied in substance abuse studies. Through a comprehensive analysis, we believe that this method offers effective tools for result interpretation thus contributing to relevant stakeholders as well as the government to better understand and hence take action to combat substance abuse problems.

\section{ACKNOWLEDGEMENTS}

The authors would like to thank Niche Research Grant Scheme (NRGS-KPM) UniSZA/NRGS/2013/RR057 for their funding of this research. A special thank goes to the Ministry of Higher Education Malaysia, Prison Department of Malaysia (Marang) and UniSZA for providing general assistants to this project. Finally yet importantly, greatly thankful to East Coast Environmental Research Institute (ESERI) upon kind assistance in data analysis techniques and peer support in completing this paper.

\section{REFERENCES}

[1] Gill J S, Rashid R A, Hui K O, Jawan R. History of illicit drug use in Malaysia-A review. International Journal of Addiction Sciences, 2010, 1(1):1-6

[2] United Nations Office on Drugs and Crime (UNODC). World drug report 2013. Vienna: UNODC, 2013

[3] Devi J P, Azriani A B, Mohd Z W, Ariff M N M, Hashimah A N. The effectiveness of methadone maintenance therapy among opiate-dependants registered with Hospital Raja Perempuan Zainab II Kota Bharu, Kelantan. Malaysian Journal of Medical Sciences, 2012, 19(4):17-22

[4] Choi P, Kavasery R, Desai M M, Govindasamy S, Kamarulzaman A, Altice F L. Prevalence and correlates of community re-entry challenges faced by HIV-infected male prisoners in Malaysia. International Journal of STD and AIDS, 2010, 21(6):416-423 
[5] Maehira Y, Chowdhury EI, Reza M, Drahozal R, Gayen T K, Masud I, Afrin S, Takamura N, Azim T. Factors associated with relapse into drug use among male and female attendees of a three-month drug detoxification-rehabilitation programme in Dhaka, Bangladesh: A prospective cohort study. Harm Reduction Journal, 2013, 10(1):1-13

[6] Mohamed M N, Marican S, Elias N, Don Y. Pattern of substance and drug misuse among youth in Malaysia. Jurnal Antidadah Malaysia, 2008, 3(4):1-56

[7] Kheradmand A, Zamani E, Hedayati N. Addiction and health exploit the developed countries experiences of primary school education to prevent drug addiction and implications for Iran. Addiction and Health, 2009, 1(1):44-51

[8] Bergen S E, Gardner C O, Aggen S H, Kendler K S. Socioeconomic status and social support following illicit drug use: Causal pathways or common liability? Twin Research and Human Genetics, 2008, 11(3):266-274

[9] Chawarski M C, Vicknasingam B, Mazlan M, Schottenfeld R S. Lifetime ATS use and increased HIV risk among not-in-treatment opiate injectors in Malaysia. Drug and Alcohol Dependence, 2012, 124(1-2):177-180

[10] Spooner C, Hetherington K. Social determinants of drug use. Technical Report, Sydney: National Drug and Alcohol Research Centre, University of New South Wales, 2004

[11] Rather Y H, Bashir W, Sheikh A A, Amin M, Zahgeer Y A. Socio-demographic and clinical profile of substance abusers attending a regional drug de-addiction centre in chronic conflict area: Kashmir, India. Malaysian Journal of Medical Sciences, 2013, 20(3):31-38

[12] Masood S, Us Sahar N. An exploratory research on the role of family in youth's drug addiction. Health Psychology and Behavioral Medicine, 2014, 2(1):820-832

[13] Humensky J L. Are adolescents with high socioeconomic status more likely to engage in alcohol and illicit drug use in early adulthood? Substance Abuse Treatment, Prevention, and Policy, 2010, 5(1):1-10

[14] Yusoff F, Sahril N, Rasidi N M, Zaki N A M, Muhamad N, Ahmad N. Illicit drug use among school-going adolescents in Malaysia. Asia-Pacific Journal of Public Health, 2014, 26(5S):100S-107S

[15] Walker L R, Mason M, Cheung I. Adolescent substance use and abuse prevention and 
treatment: Primary care strategies involving social networks and the geography of risk and protection. Journal of Clinical Psychology in Medical Settings, 2006, 13(2):126-134

[16] Wu L T. Substance abuse and rehabilitation: Responding to the global burden of diseases attributable to substance abuse. Substance Abuse and Rehabilitation, 2010, 1:5-11

[17] Rusdi A R, Noor Z M H R, Muhammad M A Z, Mohamad H H. A fifty-year challenge in managing drug. Journal of the University of Malaya Medical Centre, 2008, 11(1):3-6

[18] Pereira S M, Ambrosano G M B, Cortellazzi K L, Tagliaferro E P S, Vettorazzi C A, Ferraz S F B, Meneghim M C, Pereira A C. Geographic information systems (GIS) in assessing dental health. International Journal of Environmental Research and Public Health, 2010, $7(5): 2423-2436$

[19] Brown J S. Emerging applications of Geographic Information Systems (GIS) in community and local mental health research. Journal of Local and Global Health Perspective, 2013, 5:1-8

[20] Osei F B, Duker A A. Spatial dependency of V. cholera prevalence on open space refuse dumps in Kumasi, Ghana: A spatial statistical modelling. International Journal of Health Geographics, 2008, 7(1):1-17

[21] Kulldorff M, Feuer, E J, Miller B A, Freedman L S. Breast cancer clusters in the northeast United States: a geographic analysis. American Journal of Epidemiology, 1997, 146(2):161-170

[22] Yoshiharu F, Masahiro U, Nakamura K, Takano T. Variations in societal characteristics of spatial disease clusters: examples of colon, lung and breast cancer in Japan. International Journal of Health Geographics, 2005, 4(1):1-13

[23] Juahir H, Zain S M, Aris A Z, Yusoff M K, Mokhtar M. Spatial assessment of Langat River water quality using chemometrics. Journal of Environmental Monitoring, 2010, 12(1):287-295 [24] Simeonov V, Einax J W, Stanimirova I, Kraft J. Environmetric modeling and interpretation of river water monitoring data. Analytical and Bioanalytical Chemistry, 2002, 374(5):898-905 [25] Juahir H, Zain S M, Yusoff M K, Hanidza T I T, Armi A S M, Toriman M E, Mokhtar M. Spatial water quality assessment of Langat River Basin (Malaysia) using environmetric techniques. Environmental Monitoring and Assessment, 2011, 173(1-4):625-641 
[26] Hanchette C L, Gibbs D A, Gilliam A, Fogarty K J, Bruhn M. A national, geographic database of CDC-funded HIV prevention services: Development challenges and potential applications. International Journal of Health Geographics, 2005, 4(1):1-12

[27] Geanuracos C G, Cunningham S D, Weiss G, Forte D, Reid L M H, Ellen J M. Use of geographic information systems for planning HIV prevention interventions for high-risk youths. American Journal of Public Health, 2007, 97(11):1974-1981

[28] Sedighi M. Application of geographic information system (GIS) in analyzing geospatial information of academic library databases. The Electronic Library, 2012, 30(3) 367-376

[29] Saathoff E, Olsen A, Sharp B, Kvalsvig J D, Appleton C C, Kleinscmidt I. Ecologic covariates of hookworm infection and reinfection in rural Kwazulu-Natal/South Africa: A geographic information system-based study. American Journal of Tropical Medicine and Hygiene, 2005, 72(4):384-391

[30] Keenan P B. Spatial decision support systems. In M. Mora, G. Forgionne, \& J. N. D. Gupta (Eds.), Decision making support systems: Achievements and challenges for the new decade. Pennsylvania: IGI Global, 2002, pp. 28-39

[31] Rayed C A. Using GIS for modeling a spatial DSS for industrial pollution in Egypt. American Journal of Geographic Information System, 2013, 1(4):100-104

[32] Wilson J P, Mitasova H, Wright D J. Water resources application of geographic information systems. Urisa Journal, 2000, 12(2):61-79

[33] Jenks R H, Malecki J M. GIS-A proven tool for public health analysis. Journal of Environmental Health, 2004, 67(3):32-34

[34] Shirayama Y, Phompida S, Shibuya K. Geographic information system (GIS) maps and malaria control monitoring: Intervention coverage and health outcome in distal villages of Khammouane province, Laos. Malaria Journal, 2009, 8(1):1-8

[35] Helena B, Pardo R, Vega M, Barrado E, Fernandez J M, Fernandez L. Temporal evolution of groundwater composition in an alluvial aquifer (Pisuerga River, Spain) by principal component analysis. Water Research, 2000, 34(3):807-816 
[36] Zhao Y, Xia X H, Yang Z F, Wang F. Assessment of water quality in Baiyangdian Lake using multivariate statistical techniques. Procedia Environmental Sciences, 2012, $13: 1213-1226$

[37] Shrestha S, Kazama F. Assessment of surface water quality using multivariate statistical techniques: A case study of the Fuji river basin, Japan. Environmental Modelling and Software, 2007, 22(4):464-475

[38] Simeonov V, Stratis J A, Samara C, Zachariadis G, Voutsa D, Anthemidis A, Sofoniou M, Kouimtzis T. Assessment of the surface water quality in Northern Greece. Water Research, 2003, 37(17):4119-4124

[39] Alberto W D, María del P D, María V A, Fabiana P S, Cecilia, H A, María de los Á B. Pattern recognition techniques for the evaluation of spatial and temporal variations in water quality-A case study: Suquía River Basin (Córdoba-Argentina). Water Research, 2001, 35(12):2881-2894

[40] Vega M, Parda R, Barrada E, Deban, L. Assessment of seasonal and polluting effects on the quality of river water by exploratory data analysis. Water Research, 1998, 32(12):3581-3592

[41] Shyu G S, Cheng B Y, Chiang C T, Yao P H, Chang T K. Applying factor analysis combined with kriging and information entropy theory for mapping and evaluating the stability of groundwater quality variation in Taiwan. International Journal of Environmental Research and Public Health, 2011, 8(4):1084-1109

[42] Srivastava P K, Han D, Gupta M, Mukherjee S. Integrated framework for monitoring groundwater pollution using a geographical information system multivariate analysis. Hydrological Sciences Journal, 2012, 57(7):1453-1472

[43] Singh K P, Malik A, Mohan D, Sinha S. Multivariate statistical techniques for the evaluation of spatial and temporal variations in water quality of Gomti River (India)-A case study. Water Research, 2004, 38(18):3980-3992

[44] Kowalkowski T, Zbytniewski R, Szpejna J, Buszewski B. Application of chemometrics in river water classification. Water Research, 2006, 40(4):744-752

[45] Voss A, Witt K, Kaschowitz T, Poitz W, Ebert A, Roser P, Bar K J. Detecting cannabis 
use on the human skin surface via an electronic nose system. Sensors, 2014, 14(7):13256-13272

[46] Chung K, Yang D H, Bell R. Health and GIS: Toward spatial statistical analyses. Journal of Medical Systems, 2004, 28(4):349-360

[47] Tokatli C. Drinking water quality of a rice land in Turkey by statistical and GIS perspectives. Polish Journal of Environmental Studies, 2014, 23(6):2247-2258

[48] Corchado E, Perez JC. A three-step unsupervised neural model for visualizing high complex dimensional spectroscopic data sets. Pattern Analysis and Applications, 2011, 14(2):207-218

[49] Mahmud R, Inoue N, Sen R. Assessment of irrigation water quality by using principal component analysis in an arsenic affected area of Bangladesh. Journal of Soil and Nature, 2007, $1(2): 8-17$

[50] Cloutier V, Lefebvre R, Therrien R, Savard M M. Multivariate statistical analysis of geochemical data as indicative of the hydrogeochemical evolution of groundwater in a sedimentary rock aquifer system. Journal of Hydrology, 2008, 353(3-4):294-313

[51] Varol M. Dissolved heavy metal concentrations of the kralkizi, dicle and batman dam reservoirs in the Tigris River Basin, Turkey. Chemosphere, 2013, 93(6):954-962

[52] Di Prinzio, Castellarin A, Toth E. Data-driven catchment classification: Application to the pub problem. Hydrology and Earth System Sciences, 2011, 15(6):1921-1935

[53] Petrişor A I, Ianoş I, Iurea D, Văidianu M N. Applications of principal component analysis integrated with GIS. Procedia Environmental Sciences, 2012, 14:247-256

[54] Monjerezi M, Vogt R D, Aagaard P, Saka J D K. Hydro-geochemical processes in an area with saline groundwater in lower Shire River valley, Malawi: An integrated application of hierarchical cluster and principal component analyses. Applied Geochemistry, 2011, 26(8):1399-1413

[55] Yidana S M. Hydrochemical characterization of aquifers using sequential multivariate analyses and geographic information systems in a tropical setting. Journal of Environmental Engineering, 2011, 137(4):258-272

[56] Viero A P, Roisenberg C, Roisenberg A, Vigo A. The origin of fluoride in the granitic 
aquifer of Porto Alegre, Southern Brazil. Environmental Geology, 2009, 56(8):1707-1719

[57] Lei D, Yongzhang Z, Jin M, Yong L, Qiuming C, Shuyun X, Haiyan D, Yuanhang Y, Hongfu W. Using multivariate statistical and geostatistical methods to identify spatial variability of trace elements in agricultural soils in Dongguan City, Guangdong, China. Journal of China University of Geosciences, 2008, 19(4):343-353

[58] McNeil V H, Raymond M A A. Mapping regional groundwater chemistry zones in the Fitzroy Basin, using statistical and conceptual methods. Proceedings of the Royal Society of Queensland, 2013, 118:37-61

[59] Srinivasan K, Natesan U. Spatio-temporal variations in water quality of Muttukadu backwaters, Tamilnadu, India. Water Environment Research, 2013, 85(7):587-595

[60] Flantua S G A, Van Boxel J H, Hooghiemstra H, Van Smaalen J. Application of GIS and logistic regression to fossil pollen data in modelling present and past spatial distribution of the Colombian savanna. Climate Dynamics, 2007, 29(7-8):697-712

[61] Chen J, Lu J. Effects of land use, topography and socio-economic factors on river water quality in a mountainous watershed with intensive agricultural production in East China. Plos One, 2014, 9(8):1-12

[62] Kenu E, Ganu V, Calys T B N L, Yiran G A B, Lartey M, Richard A. Application of geographical information system (GIS) technology in the control of Buruli ulcer in Ghana. BMC Public Health, 2014, 14(1):724

[63] Goli A, Oroei M, Jalalpour M, Faramarzi H, Askaria M. The spatial distribution of cancer incidence in Fars Province: A GIS-based analysis of cancer registry data. International Journal of Preventive Medicine, 2013, 4(10):1122-1130

[64] Bao C, Liu W, Zhu Y, Liu W, Hu J, Liang Q, Wu Y, Yu R, Zhou M, Shen H, Chen F, Tang F, Peng Z. The spatial analysis on hemorrhagic fever with renal syndrome in Jiangsu Province, China based on geographic information system. Plos One, 2014, 9(9):1-8

[65] Elebead F M, Hamid A, Hilmi H S M, Galal H. Mapping cáncer disease using Geographical Information System (GIS) in Gezira State-Sudan. Journal of Community Health, 2012, 37(4):830-839

[66] Bodrud-Doza M, Islam A R M T, Ahmed F, Das S, Saha N, Rahman M S. Characterization 
of groundwater quality using water evaluation indices, multivariate statistics and geostatistics in central Bangladesh. Water Science, 2016, 30(1):19-40

[67] Li G, Weng Q. Measuring the quality of life in city of Indianapolis by integration of remote sensing and census data. International Journal of Remote Sensing, 2007, 28(2):249-267

[68] Tesfazghi E S, Martinez J A, Verplanke J J. Variability of quality of life at small scales: Addis Ababa, Kirkos sub-city. Social Indicators Research, 2010, 98(1):73-88

[69] Bell N, Schuurman N, Hayes M V, Kawachi I, Berkman L, Dunn J, Hayes M. Using GIS-based methods of multicriteria analysis to construct socio-economic deprivation indices. International Journal of Health Geographics, 2007, 6(1):1-19

[70] Boulos M N K. Towards evidence-based, GIS-driven national spatial health information infrastructure and surveillance services in the United Kingdom. International Journal of Health Geographics, 2004, 3(1):1-50

[71] Srivastava A, Nagpal B N, Joshi P L, Paliwal J C, Dash A P. Identification of malaria hot spots for focused intervention in tribal state of India: A GIS based approach. International Journal of Health Geographics, 2009, 8(1):1-8

[72] Martin V, De Simone L, Lubroth J. Geographic information systems applied to the international surveillance and control of transboundary animal diseases, a focus on highly pathogenic avian influenza. Veterinaria Italiana, 2007, 43(3):437-450

[73] Bertrand W E, Mock N B. Spatial information to make a difference: Value added decision-making in the health sector with geographical information systems. In M. J. C. de Lepper, H.J. Scholten, \& R. M. Stern (Eds.), The added value of geographical information systems in public and environmental health. Dordrecht: Springer, 1995, pp. 265-276

[74] Rosero-Bixby L. Spatial access to health care in Costa Rica and its equity: A GIS-based study. Social Science and Medicine, 2004, 58(7):1271-1284

[75] Masoodi M, Rahimzadeh M. Measuring access to urban health services using geographical information system (GIS): A case study of health service management in Bandar Abbas, Iran. International Journal of Health Policy Management, 2015, 4(47):439-445

[76] Yao J, Murray, A T, Agadjanian V. A geographical perspective on access to sexual and reproductive health care for women in rural Africa. Social Science and Medicine, 2013, 
96:60-68

[77] Higgs G. A literature review of the use of GIS-based measures of access to health care services. Health Services and Outcomes Research Methodology, 2004, 5(2):119-139

[78] Alias H, Surin J, Mahmud R, Shafie A, Zin J M, Nor M M, Ibrahim S I, Rundi C. Spatial distribution of malaria in Peninsular Malaysia from 2000 to 2009. Parasites and Vectors, 2014, $7(1): 1-7$

[79] Toriman M E, Abdullah S N F Azizan I A, Kamarudin, M K A, Umar R, Mohamad N. Spatial and temporal assessment on drug addiction using multivariate analysis and GIS. Malaysian Journal of Analytical Sciences, 2015, 6(19):1361-1373

[80] Seid A, Gadisa E, Tsegaw T, Abera A, Teshome A, Mulugeta A, Herrero M, Argaw D, Jorge A, Kebede A, Aseffa A. Risk map for cutaneous leishmaniasis in Ethiopia based on environmental factors as revealed by geographical information systems and statistics. Geospatial Health, 2014, 8(2):377-387

[81] Shafie A. Evaluation of the spatial risk factors for high incidence of dengue fever and dengue hemorrhagic fever using GIS application. Sains Malaysiana, 2011, 40(8):937-943

[82] Mason M, Cheung I, Walker L. Substance use, social networks, and the geography of urban adolescents. Substance Use and Misuse, 2004, 39 (10-12):1751-1777

[83] Trooskin S, Hadler J, St Louis T, Navarro V. Geospatial analysis of hepatitis C in Connecticut: A novel application of a public health tool. Public Health, 2005, 119(11):1042-1047

[84] Latkin C, Glass G E, Duncan T. Using geographic information systems to assess spatial patterns of drug use, selection bias and attrition among a sample of injection drug users. Drug and Alcohol Dependence, 1998, 50(2):167-175

[85] Green T C, Pope C. Using a GIS framework to assess hurricane recovery needs of substance abuse center clients in Katrina- and Rita-affected areas. In Y. F. Thomas, D. Richardson, \& I. Cheung (Eds.), Geography and drug addiction. New York: Springer Science+Business Media, 2008, pp 369-393

[86] Perron B E, Gillespie D F, Alexander-Eitzman B, Delva J. Availability of outpatient substance use disorder treatment programs in the United States. Substance Use and Misuse, 
2010, 45(7-8):1097-1111

[87] Guerrero E G, Pan K B, Curtis A, Lizano E L. Availability of substance abuse treatment services in Spanish: A GIS analysis of Latino communities in Los Angeles County, California. Substance Abuse Treatment, Prevention, and Policy, 2011, 6(1):1-8

[88] Guerrero E G, Kao D, Perron B E. Travel distance to outpatient substance use disorder treatment facilities for Spanish-speaking clients. International Journal Drug Policy, 2013, 24(1):38-45

[89] Brouwer K C, Weeks J R, Lozada, Strathdee A. Chapter 3: Integrating GIS into the study of contextual factors affecting injection drug use along the Mexico/US border. In Y. F. Thomas, D. Richardson, \& I. Cheung (Eds.), Geography and drug addiction. New York: Springer Science+Business Media, 2008, pp. 27-42

[90] Chikumba P. A. Application of geographic information system (GIS) in drug logistics management information system (LMIS) at district level in Malawi: Opportunities and challenges. In A. Villafiorita, R. Saint-Paul, \& A. Zorer (Eds.), E-infrastructures and e-services on developing countries. Lecture Notes of the Institute for Computer Sciences, Social Informatics and Telecommunications Engineering, Berlin: Springer, 2009, pp. 105-115

[91] Colasante E, Molinaro S, Mariani F. Spatial analysis of drug-related hospital admissions: An auto-Gaussian model to estimate the hospitalization rates in Italy. Italian Journal of Public Health, 2008, 5(4):253-260

[92] Mendoza N S, Conrow L, Baldwin A, Booth J. Using GIS to describe risk and neighbourhood-level factors associated with substance abuse treatment outcomes. Journal of Community Psychology, 2013, 41(7):799-810

[93] Kao D, Torres L R, Guerrero E G, Mauldin R, Bordnick P S. Spatial accessibility of drug treatment facilities and the effects on locus of control, drug use, and service use among heroin-injecting Mexican American men. International Journal Drug Policy, 2014, 25(3):598-607

[94] Toner P, Velleman R. Initial reliability and validity of a new measure of perceived social support for family members of problem substance users. Addiction Research and Theory, 2014, 
22(2):147-157

[95] González-Saiz F, García-Valderrama T. The Opiate Treatment Index (OTI) clinical interview: New evidence of its reliability and validity. Heroin Addiction and Related Clinical Problems, 2012, 14(2):19-34

[96] Hensen W B. School-based substance abuse prevention: A review of the state of the art in curriculum, 1980-1990. Health Education Research, 1992, 7(3):403-430

[97] David M P, Chondra L M. Advances in statistical methods for substance abuse prevention research. Society for Prevention Research, 2003, 4(3):155-171

\section{How to cite this article:}

Fazillah A, Juahir H, Toriman E, Mohamad N, Mohamad M.Combating substance abuse with the potential of geographic information system combining multivariate analysis. J. Fundam. Appl. Sci., 2017, 9(2S), 485-504. 